\title{
Strategy Research on Comprehensive Control for the Building Indoor Environment based on PMV Index and Body Suitability Regulator
}

\author{
Guo Tongying* \\ Shenyang Jianzhu University \\ Shenyang, China \\ e-mail: arnold0110@ sina.com \\ * Corresponding Author \\ Zhao Languang \\ Shenyang Jianzhu University \\ Shenyang, China
}

\author{
Chen $\mathrm{Lu}$ \\ Shenyang Jianzhu University \\ Shenyang, China \\ Wang Xin \\ Shenyang Jianzhu University \\ Shenyang, China
}

\begin{abstract}
Building indoor environmental can directly affect people's health and work efficiency, so the research on building indoor environmental control has obvious significance. The paprameters of indoor environment control includes not only temperature, humidity and other parameters, but also $\mathrm{CO} 2$ concentrations, formaldehyde concentrations and other air quality paprameters. For the energy saving requirement, in this paper,a method is proposed based on PMV (Predicted Mean Vote Average rating forecast) and human adaptability regulation. Comparative analysis shows that this method proposed can not only improve the indoor temperature, humidity, increase fresh air, improve indoor air quality, but also save more energy than traditional methods.
\end{abstract}

Keywords-PMV; human adaptability; ventilation; environmental control;air-conditioned

\section{INTRODUCTION}

In modern society, most people spend more than $80 \%$ of the lifetime indoors. With the continuous economic development and improve living standards, people have higher demand of comfortable indoor environment.

The past century, with the emergence and development of air-conditioning technology enables to provide a comfortable indoor environment becomes a reality through artificial means for humanity. However, the extensive use of air conditioning, it also brings many problems. For example, it was long in air-conditioned environment caused throat irritation, nasal congestion related symptoms, headache, dizziness, nausea, chest tightness, fatigue, etc., that Sick Building Syndrome (SBS, Sick Building Syndrome); on the other hand, airconditioning energy consumption a substantial increase in the amount. In central China, south and east and other regions, air-conditioning power consumption accounts for about $1 / 3$ of the entire city, while in Beijing, Shanghai and other cities of the air conditioning load even once accounted for more than $40 \%$ of the power consumption of the entire city. Among them, the energy consumption of the building's air conditioning system to account for about $55 \%$ of total energy consumption of the building [13].
Natural ventilation as a cheap and proven ventilation technology again gained in importance. And rational use of natural ventilation can without consuming any nonrenewable energy effectively reduce the indoor temperature to ensure thermal comfort, help to further reduce energy consumption. For the comfort of air conditioning is concerned, most of the time in the year, such as the transition season, relying on natural ventilation only be able to fully meet the needs of human comfort. Existing survey data show [5], in office buildings if the use of natural ventilation, cooling capacity per year savings $14 \sim 41 \mathrm{kWh} / \mathrm{m}^{2}$, cost savings of approximately $\$ 1.3 \sim 3.6 / \mathrm{m}^{2}$. In addition, the International Energy Agency (IEA) in 2000 annual summary report that natural ventilation can reduce office building energy consumption in European countries up to 50\% [6]. On the other hand natural ventilation can provide fresh, clean air (outdoor air), to meet the psychological needs of humans and nature interact, reflects the sustainable development and human return to nature, the pro and natural philosophy, and in favor of human psychology and physical health [710]. To this end, we should re-examine the nature of the scientific issues of air-conditioned environment.

In recent years, the development of computer simulation technology enables prediction of natural ventilation in the feasibility of different indoor climate and ventilation Demand possible, but with the development of building automation technology, outer window can automatically open, so natural ventilation without human participation can be realized. But now optional on the ventilation system is too simple, in fact, a combination of different ventilation systems will become more effective in regulating the indoor environment, and thus in the outdoor climate, building use, location and other conditions are different, can different design combinations to solve the stability of poor natural ventilation defects.

There are methods for the study of indoor air environment mainly in two ways: First, in a controlled laboratory studies based on micro-climate chamber; the second is exposure to the actual environment field research methods. This article will focus on the center of 
the scene of a demonstration of energy-saving practical to collect data, the study of natural ventilation, multivariate optimization of mechanical ventilation and air conditioning systems of control problems.

\section{PMV INDEX}

Professor Fanger of 1396 subjects in the United States and Denmark indoor climate parameters stable artificial indoor thermal comfort feeling of coldness experiment data presented PMV (PredietedMeanVote expected average evaluation) test regression formula, see equation (1).

$$
\begin{aligned}
P M V= & {[0.303 \exp (-0.036 \mathrm{M})+0.0275] \mathrm{X}\{\mathrm{M}-\mathrm{W}-3.05[5.733-} \\
& \left.0.007(\mathrm{M}-\mathrm{W})-\mathrm{P}_{\mathrm{a}}\right]-0.42[(\mathrm{M}-\mathrm{W})-58.15) \\
& -0.0173 \mathrm{M}\left(5.867-\mathrm{P}_{\mathrm{a}}\right)-0.0014 \mathrm{M}\left(34-\mathrm{t}_{\mathrm{a}}\right) \\
& \left.-3.96 \times 10^{-8} \mathrm{f}_{\mathrm{cl}}\left[\left(\mathrm{t}_{\mathrm{cl}}+273\right)^{4}-\left(\mathrm{t}_{\mathrm{r}}+273\right)^{4}\right]-\mathrm{f}_{\mathrm{cl}} \mathrm{h}_{\mathrm{c}}\left(\mathrm{t}_{\mathrm{cl}}-\mathrm{t}_{\mathrm{a}}\right)\right\} \quad(1)
\end{aligned}
$$

In the formula,

M: human energy metabolic rate (depending on the size of the activity);

W: mechanical work done by the body;

Pa: water vapor pressure around the body of air (relative humidity of the air related);

ta: the body temperature of the ambient air;

fcl: wear body appearance than the clothes area with its naked surface area, called area coefficient clothing;

tcl 1: clothes outside surface temperature;

tr: mean radiant temperature;

hc: convective heat transfer coefficient.

PMV as the characterization of human feeling comfortable thermal environment evaluation, which the human factor (the amount of activity and the clothes) and indoor environmental factors (air velocity, mean radiant temperature, indoor temperature, indoor humidity) are related. Currently PMV has been widely used in indoor air-conditioned comfort of the definition. 6 elements of the relationship between comfort and PMV shown in Fig. 1 .

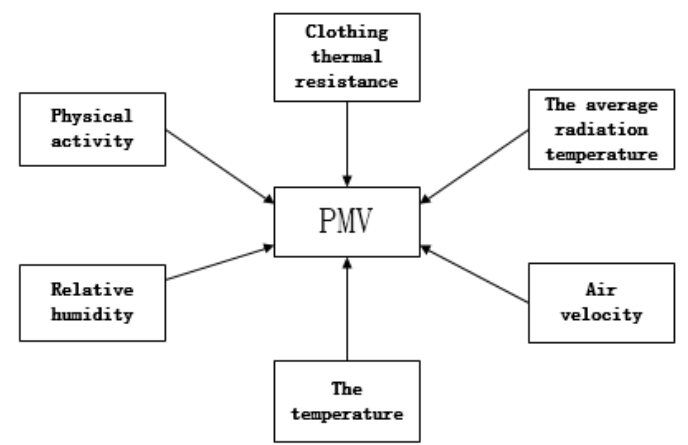

Figure 1. six elements of comfort and PMV relationship diagram

In fact, Fanger at the launch of the experimental regression formula PMV, the human thermal comfort experimental data are used in the air conditioning system in the room parameters strictly controlled artificial climate indoor obtained. Indoor experiment parameters stable and uniform, and therefore experiments PMV regression formula applies only to indoor parameters stable and uniformly distributed around the body of the thermal environment, not applicable to non-stable thermal environment, it does not apply to non-parametric around the body uniform thermal environment.

\section{HUMAN ADAPTING}

Adaptive behavior in people's daily life is extremely common behavior listed below are British response to cold or heat change, these actions include all aspects of the mental, physical, social and behavior in different regions according to local as appropriate modifications.

It said adaptive behavior is divided into the following five categories:

- Regulating metabolic rate;

- Adjust the thermal environment;

- Regulate body heat loss;

- Select a different thermal environment;

- Improve their physical comfort criteria (adapt to different environments).

Adaptive behavior of a variety of thermal comfort, the role of each of adaptive behavior is small, people can simultaneously combine several different behaviors to achieve thermal comfort, regulate the behavior of individuals to maintain thermal comfort plays an active role. In this study, questionnaires, behavior adaptability office building staff conducted survey results shown in Tab. 1.

TABLE I OFFICE STAFF ADAPTIVE BEHAVIOR SURVEY

\begin{tabular}{cccccc}
\hline $\begin{array}{c}\text { Sritch Windows } \\
\text { and doors }\end{array}$ & $\begin{array}{c}\text { The air } \\
\text { conditioning }\end{array}$ & $\begin{array}{c}\text { Increase or } \\
\text { decrease } \\
\text { in dress }\end{array}$ & $\begin{array}{c}\text { Drink cold } \\
\text { (hot) drink }\end{array}$ & $\begin{array}{c}\text { Lunch } \\
\text { break }\end{array}$ & $\begin{array}{c}\text { Increase or } \\
\text { decrease in } \\
\text { physical activity }\end{array}$ \\
\hline $84 \%$ & $49 \%$ & $64 \%$ & $40 \%$ & $15 \%$ & $9 \%$ \\
\hline
\end{tabular}

Table way in this survey statistics office building staff are given an adaptive behavior. You can see people in order to make the body more comfortable in the office environment, will take various measures to adapt themselves to changes in the indoor environment, they on the one hand by adjusting itself, such as changes in dress, drink and so on; on the other hand will use initiative adjust the way the indoor environment, such as switching windows, air conditioning and other measures to make the environment as much as possible to reach people feel comfortable state. Results from the survey can be found in adaptive behaviors among workers in office buildings in the most common measure is to switch windows, where about $84 \%$ of the subjects would choose to switch windows to regulate the indoor environment. Although the air-conditioned environment indoor thermal comfort in good condition, but most participants believed interior doors and windows closed air-conditioned environment easily lead to deterioration of indoor air quality situation, so the survey only $49 \%$ of the subjects would choose to use the air conditioning. There are also $64 \%$ of the subjects would choose changes in dress, $40 \%$ of the subjects choose to drink cold (hot) drink to improve their thermal comfort condition. The lunch break and increase (decrease) the amount of exercise, etc. occupy a smaller proportion, adaptive behavior and characteristics of 
visible office staff work closely linked, office building staff priorities through natural ventilation, changes in dress these natural ways to get the body comfort.

\section{INDOOR ENVIRONMENT CONTROL STRATEGY}

\section{A. Experimental Platform}

In this study, a demonstration of energy-saving building for the study, the building on the ground floors, basement, building area $1600.73 \mathrm{~m}^{2}$. The building indoor ventilation tissue schematically shown in Fig. 2. Outside the window area can be opened up to $49.29 \%$, it has openable skylight atrium, effectively improve air atrium environment. After simulation analysis, the major uniform flow in a room, no dead ends. The ventilation system can not only improve indoor air quality situation, but also improve the thermal environment. Indoors there is temperature, humidity, $\mathrm{CO}_{2}$ concentration monitoring and control device, through the building control system linkage and ventilation systems and air conditioning systems, thus ensuring good indoor air quality. Wherein the temperature, humidity, $\mathrm{CO}_{2}$ concentration data collected in the field, the sensor uses Siemens QFA2060D type room temperature and humidity sensors and Siemens QPA2002D type $\mathrm{CO}_{2}$ concentration monitoring devices.

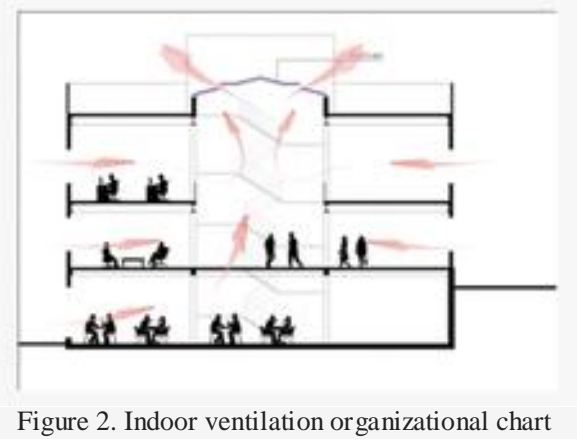

\section{B. Integrated Control}

The new concept of ventilation and air conditioning control strategy combines the advantages of multivariate main ventilation and dynamic air-conditioning, and a reasonable basis for the use of renewable energy and waste heat up to achieve indoor air environmental parameters dynamically adjusted to regulate the indoor environment cascade thermal comfort and indoor air quality The IAQ (including $\mathrm{CO} 2$ concentrations, dust concentration, the $\mathrm{CO} 2$ concentration of the control scheme only for example) as the goal, indoor temperature and humidity, wind speed indoor, indoor $\mathrm{CO} 2$ concentrations based on four main parameters of the indoor environment integrated control. 4 control parameters as indoor $\mathrm{CO} 2$ concentration - indoor wind speed - acceptable temperature - the order will be stepwise control indoor humidity. The measured value is compared with the set value of each parameter to determine specific forms and methods of use of energy. The kinds of control method can also consider the impact of wind speed, wind direction and rainfall intensity by the method of the control signal, as amended.
It should be noted that each of these control procedures and parameters should be based on the finalization of a large number of experimental tests and procedures to run, in order to detect the Run whether the conflict between the various parameters, if the conflict is the proportion of the relationship between the parameters of basis, in accordance "Stay primary to secondary" principle, ensure that the main parameters of the regulation can be performed smoothly. Eventually to meet the indoor comfort and air quality requirements, while the true realization of energy cascade utilization. Adaptive behavior and relationships in thermal sensation in the Fig.3

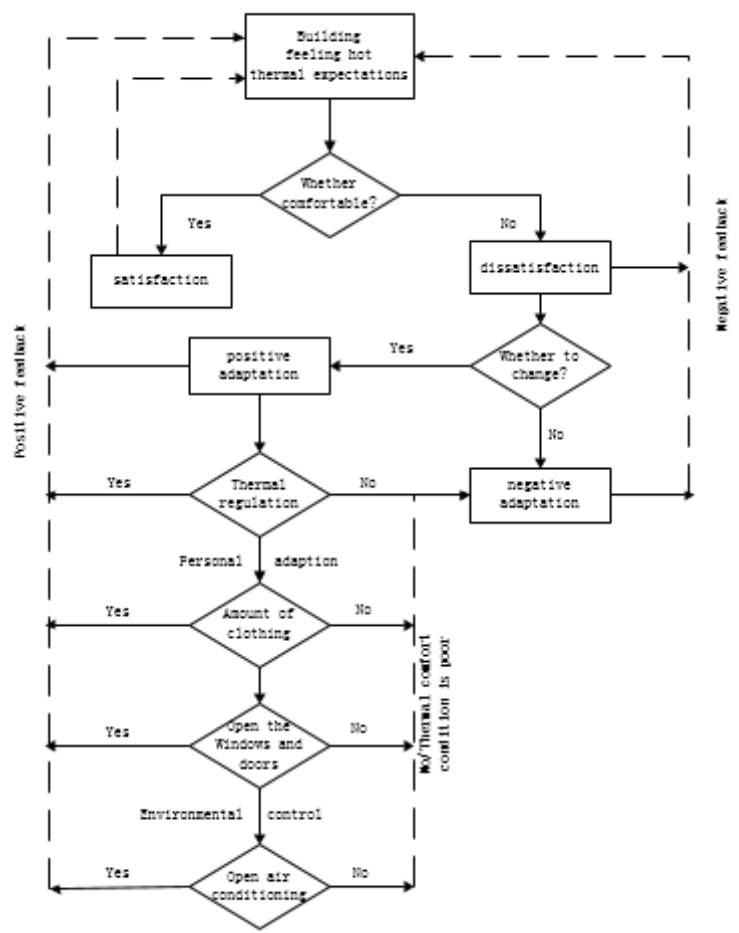

Figure 3. Adaptive behavior and thermal sensation graph

\section{Analysis}

In the actual test, the building interior to achieve intelligent control, temperature, humidity and wind speed to meet the requirements of the design of indicators.

Therefore, the body heat and moisture environment in which adaptation is a very complex process. Between the human body and the environment, the role of both the thermodynamic process of heat and mass transfer, someone's subjective awareness of and physiological adjustment process objectively. For the study of indoor thermal environment, which requires an objective assessment of the environment (such as air temperature, humidity and wind speed, etc.), but also should reflect the subjective evaluation of the surrounding environment. Only a combination of both, and can be quantified objective and fair conclusion to give the body the real needs of the environment.

Current thermal comfort standards and building heat index does not fully take into account the capacity of human adaptability, to establish uniform thermal comfort zone and fixed environmental parameters (temperature, humidity, wind speed) design value. Obviously, this is 
unrealistic and not conducive to human thermal comfort and energy efficiency in buildings. For the contradiction between comfort and energy efficiency should be the premise of ensuring human comfort, seek the optimal allocation of human thermal comfort and energy efficiency in buildings. In fact, the body's ability to adapt to the environment has an adjustment range within which active regulation related indoor environmental parameters, the body will be able to combine the flexibility and building energy efficiency.

\section{CONCLUSION}

Human thermal environment for a certain ability to adapt, by comparing discoveries PMV PMV and TSV model By ignoring the potential of human adaptation, thermal comfort can not be a true reflection of the situation of personnel.

Finally, adaptive behavior by staff within the office building of the survey as well as natural ventilation and air conditioning and ventilation were compared after, and in accordance with the theory of pluralism ventilation and dynamic air conditioning, ventilation and air conditioning, a novel control strategy to meet the indoor comfort and At the same time air quality requirements, achieve cascade utilization of various energy.

\section{REFERENCES}

[1] Liang C H, Zhang L Z, Pei L X. Independent air dehumidification with membrane-based total heat recovery: modeling and experimental validation[J]. International Journal of Refrigeration, 2010, 33(2): 398-408.

[2] Ouyang G, Wu J, You S, et al. Feasibility Analysis of Application of Combined Chilled Ceilings and Displacement Ventilation Systems in South-China[J]. Energy Procedia, 2011(11): 4987-4995.

[3] Laverge J, Van Den Bossche N, Heijmans N, et al. Energy Saving Potential and Repercussions on Indoor Air Quality of Demand Controlled Residential Ventilation Strategies[J]. building and environment, 2011, 46(7): 1497-1503.

[4] Cao L Y, Wu J H, Hu Y, et al. Cooling Effect of Mechanical Ventilation in Grape Greenhouse Based on CFD Numerical Simulation[J]. Applied Mechanics and Materials, 2014, 448: 2890-2896.

[5] Zhou L, Haghighat F. Optimization of Ventilation Systems in Office Environment, Part II: Results and discussions[J]. Building and Environment, 2009, 44(4): 657-665.

[6] D. Mumovic.Winter indoor air quality, thermal comfort and acoustic performance of newly built secondary schools in England[J].Building and Environment,2009,44:1466-1477.

[7] Zhaojun Wang,Lin Zhang,Jianing Zhao,Yanan He.Thermal comfort for naturally ventilated residential buildings in Harbin[J].Energy and Buildings,2010(42):2406-2415.

[8] A. Abd Razak, A. Hagishima, N. Ikegaya, et al. Analysis of Airflow over Building Arrays for Assessment of Urban Wind Environment[J]. Building and Environment, 2013(59): 56-65.

[9] E. Gallego, F. Roca, J. Perales, et al. Experimental Evaluation of Voc Removal Efficiency of a Coconut Shell Activated Carbon Filter for Indoor Air Quality Enhancement[J]. Building and Environment, 2013(67): 14-25.

[10] C. Ritter, C.K. Huynh, J.F. Etter, et al. Exposure to Tobacco Smoke before and after a Partial Smoking Ban in Prison: Indoor Air Quality Measures[J]. Tobacco control, 2012, 21(5): 488-491. 